\title{
Simultaneous Electricity Generation and Microbially-Assisted Electrosynthesis in ceramic MFCs
}

\author{
Iwona Gajda ${ }^{\mathrm{a}}$, John Greenman ${ }^{\mathrm{a}, \mathrm{b}}$, Chris Melhuish $^{\mathrm{a}}$, Ioannis Ieropoulos ${ }^{\mathrm{a}, \mathrm{b}}$ \\ ${ }^{a}$ Bristol Robotics Laboratory, Block T, UWE, Bristol, Coldharbour Lane, Bristol BS16 1QY, \\ $U K$ \\ ${ }^{b}$ School of Life Sciences, UWE, Bristol, Coldharbour Lane, Bristol BS16 1QY,UK \\ *ioannis.ieropoulos@brl.ac.uk \\ *Corresponding author: Tel.: +44 11732 86318, 86322; Fax: +44 1173283960 E-mail \\ address: ioannis.ieropoulos@brl.ac.uk (I. Ieropoulos) \\ Bristol Robotics Laboratory, T-Building, Frenchay Campus, Bristol, BS16 1QY, UK
}

\section{Abstract}

To date, the development of microbially assisted synthesis in Bioelectrochemical Systems (BES) has focused on mechanisms that consume energy in order to drive the electrosynthesis process. This work reports - for the first time - novel ceramic MFC systems that generate electricity whilst simultaneously driving the electrosynthesis of useful chemical products. A novel, inexpensive and low maintenance MFC demonstrated electrical power production and implementation into a practical application. Terracotta based tubular MFCs were able to produce sufficient power to operate an LED continuously over a 7 day period with a concomitant $92 \%$ COD reduction. Whilst the MFCs were generating energy, an alkaline solution was produced on the cathode that was directly related to the amount of power generated. The alkaline catholyte was able to fix $\mathrm{CO} 2$ into carbonate/bicarbonate salts. This approach implies carbon capture and storage (CCS), effectively capturing $\mathrm{CO} 2$ through wet caustic 'scrubbing' on the cathode, which ultimately locks carbon dioxide.

Key words: terracotta MFC, wet scrubbing, catholyte generation, water recovery, microbially assisted electrosynthesis

\section{Introduction}

The cost of energy generation and wastewater treatment is expected to increase in the near future, in order to meet the growing global population and the resultant demand on resources. 
The treatment of wastewater is typically viewed as an energy intensive burden rather than a

resource. The energy value of domestic wastewater can be up to $7.6 \mathrm{~kJ}$ per litre $(\mathrm{kJ} / \mathrm{L})$ and that of mixed industrial and domestic wastewater as much as $16.8 \mathrm{~kJ} / \mathrm{L}$ [1]. By harnessing the energy in wastewater, the water industries can become more efficient both financially and environmentally. In addition, wastewater could become a source of energy in parts of the world, which currently lack the essential infrastructure for reliable and affordable energy generation and distribution. Globally, there is an urgent need for low-cost water treatment technologies both in developed and developing countries.

Research in the field of Bioelectrochemical Systems (BES) has focused on converting compounds in wastewater to bioelectricity via Microbial Fuel Cell (MFC) or other energetically valuable products [2]. Properties of the proton selective membrane and its configuration in dual-chamber MFC offer the opportunity to transfer cations from the anolyte over to the cathode [3]. In this way the cathode can be exploited as a mechanism for removing specific contaminants e.g. heavy metals [4]. This can be taken a step further by supplying an external energy into the BES system, where valuable products such as hydrogen gas [5], hydrogen peroxide [6], methane [7] or caustic soda [5,8] can be recovered. The formation of caustic soda for example, is driven by the alkalinisation on the cathode side due to the continuous consumption of protons by the oxygen reduction reaction (ORR) and cationic flux [3]. In general, ORR on the carbon based cathodes proceeds either via the twoor four- electron pathway. The 4-electron pathway appears to be predominant on noble metal catalysts, whilst the 2-electron pathway, known as peroxide pathway is more common on carbon based electrodes. In acidic conditions, it will result in formation of hydrogen peroxide which is further reduced to water. In alkaline environment it will result in generation of $\mathrm{OH}-$ [9] that leads to a further increase in $\mathrm{pH}$. MFC operation causes not only transport of ions (protons and cations) but also flow of liquid through the membrane, which leads to the so called electroosmotic transport of water [10]. This has resulted in many recent studies moving away from electricity generation and instead focussing on electricity consumption via Microbial Electrolysis Cells, where microbially assisted electrosynthesis can effectively be used for the production of oxidants or disinfectants [11] or even water dissociation via electrodialysis for separating the ionic species. However, it has recently been reported that the same process of microbially driven electrosynthesis can be achieved with both energy production and simultaneous elemental recovery in a simple MFC design [12]. This process generated a highly saline catholyte that additionally acted as a dragging mechanism, similar 
osmosis membranes, $\mathrm{NaCl}$ as the catholyte solution and usually, platinum electrodes. OsMFC represents a water extraction technology, which can recover water molecules from the anolyte through the membrane via osmotic pressure [13]. This relies on Forward Osmosis (FO), where the osmotic pressure gradient that exists between solutions of two different concentrations is driving the transport of water across the membrane. The driving force is created by high solute concentration solution and water transport occurs naturally via electro passive transport. In OsMFC, externally supplied salt solution is used as catholyte and has been shown to increase current generation [14], however the disadvantage of FO reactors is the salt leakage across the membrane [15].

Wastewater, as an abundant biological resource has the enormous potential for clean energy, and its treatment is an important benefit of this process. In order for the MFC technology to be feasible and implemented in real world conditions, the performance needs to be improved and its design has to be simplified to become cost effective for practical use. To explore this path further it is important to look into cost effective materials, design and methodology to showcase the technology as a serious contender for practical implementation in wastewater treatment plants. For example, ceramic material have been recognised as a low cost alternative to PEM and used as septum/separator [16] or as a whole MFC reactor [17-20]. In addition, the electrode material is another critical factor of the MFC architecture that plays an important role in performance, cost of production and preparation, as well as longevity and maintenance. In this respect, activated carbon based cathodes are inexpensive and useful alternatives to Pt-catalyzed electrodes in MFCs [21-24].

The aims of this work were therefore to: i) develop a simple, ceramic based MFC design as an immersed anode in a wastewater tank for both energy recovery and microbially driven electrosynthesis of catholyte; ii) explore simple and cost effective designs based only on carbon electrodes and ceramic materials, iii) demonstrate the catholyte generation in situ within the catholyte chamber as a means of water recovery and carbon capture.

\section{Materials and methods}

2.1. MFC design and operation MFCs were built using terracotta caves (Orwell Aquatics, UK) of $10 \mathrm{~cm}$ length, $4.2 \mathrm{~cm}$ outside diameter, $3.6 \mathrm{~cm}$ inside diameter and the wall thickness of $3 \mathrm{~mm}$. They were assembled with carbon veil anode and activated carbon cathode. The anode electrode was made of carbon veil $20 \mathrm{~g} / \mathrm{m}^{2}$ (PRF Composite Materials, Dorset, UK), size $2430 \mathrm{~cm}^{2}$. The electrode was folded down, wrapped around the terracotta cave, and it was held in place with 
nickel chromium wire $(0.45 \mathrm{~cm}$ diameter $)$ as shown in Figure 1 . The MFCs were placed inside a container filled with $200 \mathrm{~mL}$ of activated sludge provided by Wessex Water Scientific
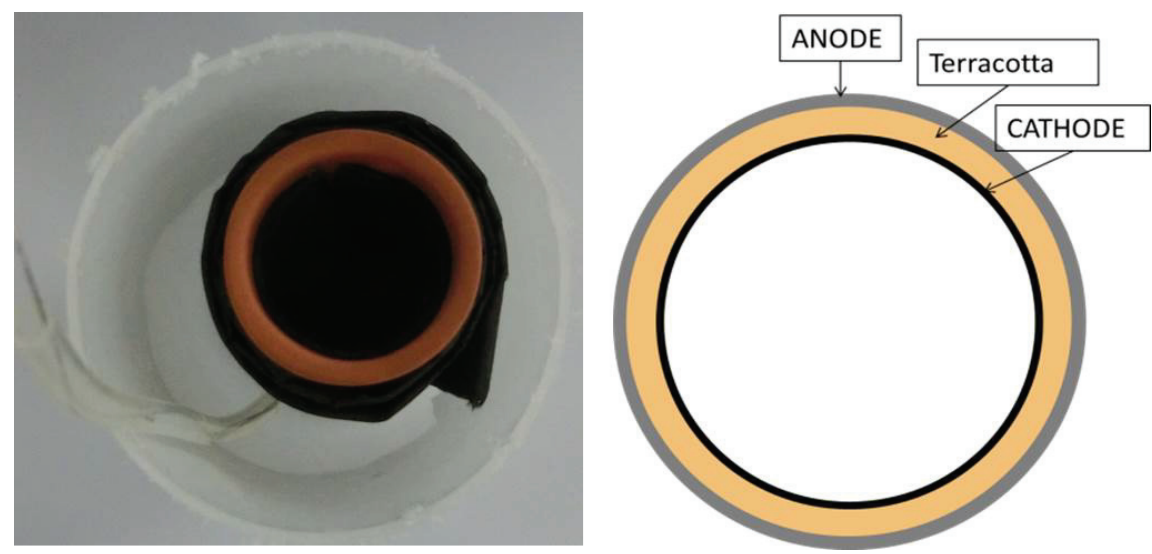

Figure 1. The ceramic MFC assembled and its schematic description.

\subsection{Cathode preparation}

111 To optimise the cost and performance of the cathode electrode, carbon veil was used as gas

112 diffusion layer (GDL) replacing the more expensive carbon cloth. Carbon veil sheet was pre-

113 treated by coating with 30\% PTFE (Sigma Aldrich) solution and left to dry. This material was

114 used as the current collector and GDL. Afterwards, it was coated with activated carbon and

$11520 \%$ PTFE mixture on one side only. The mixture was prepared by combining $80 \mathrm{~g}$ of

116 activated carbon powder (G. Baldwin and Co., London, UK) and $20 \%$ wt PTFE (60\% PTFE

117 dispersion in water -Sigma Aldrich, UK) in deionised water. The prepared mixture was

118 applied onto the pre-treated carbon veil and distributed with a spatula. The obtained loading

119 of activated carbon was $\sim 60 \mathrm{mg} / \mathrm{cm}^{2}$. The AC/PTFE mixture and carbon veil were hot

120 pressed at $150-200{ }^{\circ} \mathrm{C}$ using a household iron until the coated material was completely dry

121 (Figure 2). 

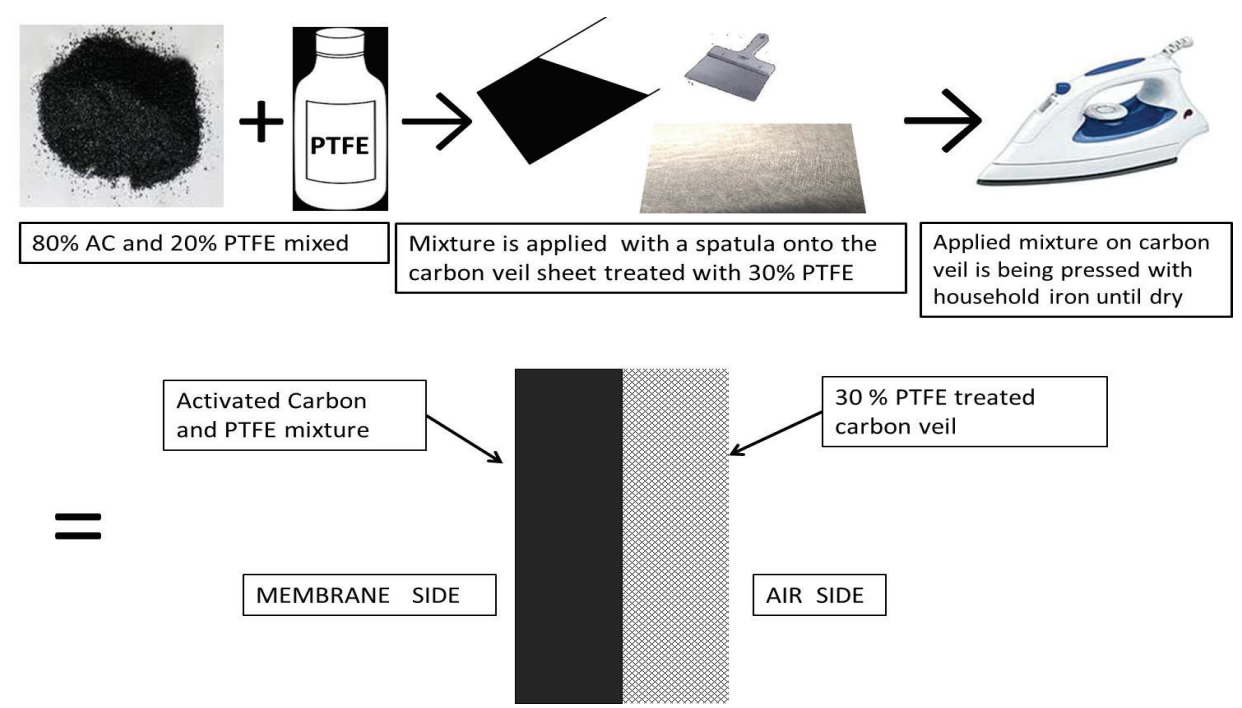

Figure 2. Cathode electrode preparation procedure

124 The cathodes were then cut in $90 \mathrm{~cm}^{2}$ pieces and placed inside the MFC cylinders so the 125 activated carbon layer faced the inside of the terracotta wall. Electrodes were connected to

126 the data logging equipment via nickel chromium wires and stainless steel crocodile clips.

128 Polarisation experiments were performed using a Resistorstat tool [25] in the range of $30 \mathrm{k} \Omega$

129 to $10 \Omega$ and the time constant for each resistance value was 3 minutes. Data were logged using

130 a multi-channel Agilent 34972A, LXI Data Acquisition/Switch Unit (Farnell, UK) and

131 processed using the Microsoft Excel and GraphPad Prism software packages. Current and

132 power were calculated as previously described [26].

133 For the purposes of demonstrating the feasibility of the tested MFCs as the sole power source

134 for applications, a single red LED (RS, UK) was connected directly to the MFC without the 135 use of any energy harvesting system.

136 2.4. Analysis

137 The $\mathrm{pH}$ was measured with Hanna $8424 \mathrm{pH}$ meter (Hanna, UK) and the conductivity with 138470 Jenway conductivity meter (Camlab, UK). Dry weight of precipitated salts was 139 determined by drying $0.5 \mathrm{~mL}$ of catholyte over $48 \mathrm{~h}$ and weighing the dry mass. Energy

140 dispersive X-ray (EDX) analysis was performed (Philips XL30 SEM) and was used to 141 determine elements present in crystallised cathodic salts. Detection limits are typically 0.1$142100 \%$ wt. X-ray diffraction (XRD) analysis on precipitated salts from the catholyte was 
143 determined using powder measurements, performed on a Bruker D8 Advance Diffractometer with the results analysed using EVA software package (Bruker, UK).

145 COD was determined using the potassium dichromate oxidation method (COD HR test vials, 146 Camlab, UK) and analysed with a MD 200 photometer (Lovibond, UK) where $0.2 \mathrm{~mL}$ samples were taken before and during MFC treatment and filter-sterilised prior to analysis.

\subsection{Power performance}

152 A triplicate of MFCs were continuously operated under external load conditions from the 153 beginning (T1, T2, T3), whereas the second triplicate set (T4, T5, T6) was left under open

154 circuit conditions. In order to evaluate the electricity generation of this system, the

155 polarisation experiments were performed only on the working MFCs and are shown in Figure

156 3. The best performance $2.58 \mathrm{~mW}\left(286 \mathrm{~mW} / \mathrm{m}^{2}\right)$ was achieved by $\mathrm{T} 1$, whereas $\mathrm{T} 2$ generated

$1572.12 \mathrm{~mW}\left(235 \mathrm{~mW} / \mathrm{m}^{2}\right)$ and T3 gave $1.16 \mathrm{~mW}\left(128 \mathrm{~mW} / \mathrm{m}^{2}\right)$. The MFCs under open circuit

158 conditions were used to assess the passive dialysis effects, i.e. the passive diffusion of anolyte 159 through the porous structure of the terracotta chassis.

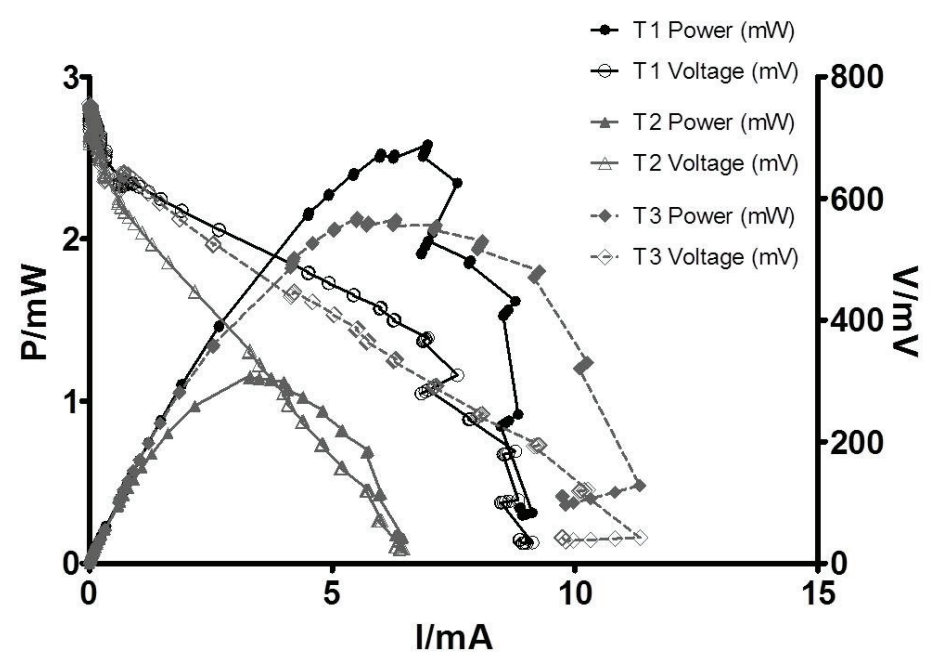

161 Figure 3. Polarisation curves performed during MFCs were operated using sodium acetate and wastewater mixture.

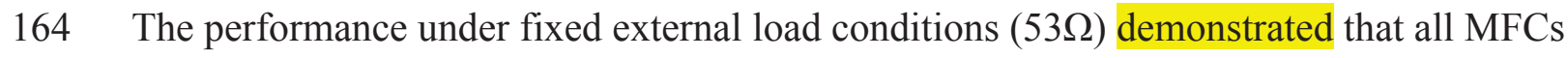
165 exhibited stable performance over a 7 day period, during which, catholyte formed on the 166 surface of the cathode (Fig. 5A). The current generated during this time was T1 $7.12 \mathrm{~mA}$, T2 
$1674.50 \mathrm{~mA}$ and T3 $6.09 \mathrm{~mA}$, which was proportional to the amount of catholyte generated (Fig.

168 4A); T1 produced $68 \mathrm{~mL}, \mathrm{~T} 245 \mathrm{~mL}$ and T3 produced $55 \mathrm{~mL}$ of clear catholyte. The MFCs in

169 open circuit mode showed some catholyte accumulation, however in significantly smaller

170 volumes (Fig. 4B); T4 produced 15mL, T5 $17 \mathrm{~mL}$ and T6 generated $10 \mathrm{~mL}$ of catholyte. This

171 is most likely due to passive diffusion, since no charge transfer was occurring under open

172 circuit conditions. During this time the amount of anolyte lost was proportional to the

173 accumulated catholyte, and thus the MFC performance. This is in agreement with the

174 previously published work that reported on catholyte generation [12].

\section{A}

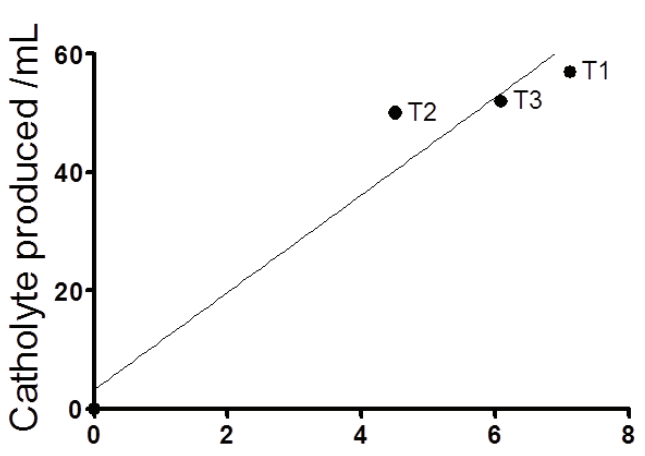

Current $/ \mathrm{mA}$
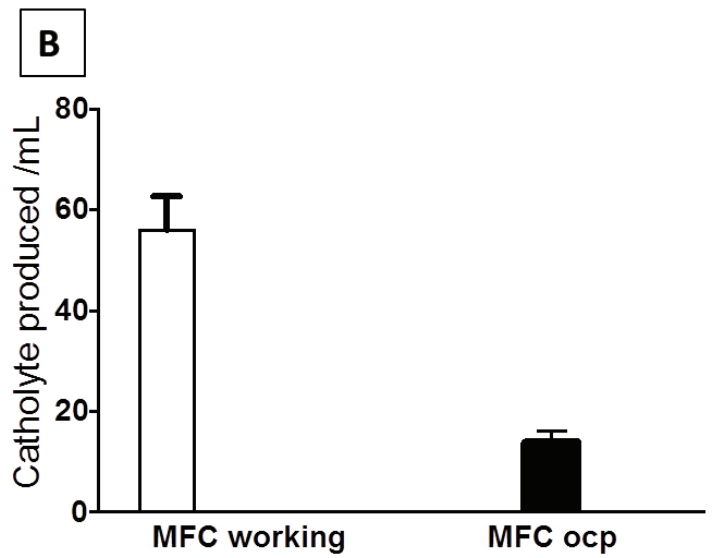

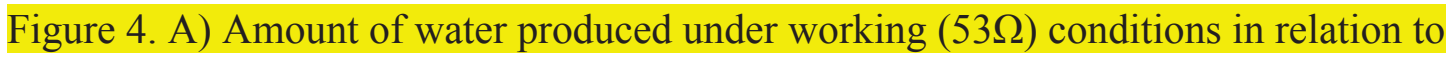

current; B) comparison of the amount of catholyte produced in closed and open circuit conditions

\subsection{Catholyte analysis}

181 Only the cathode electrodes in the working MFCs showed clear production of droplets directly on the surface of the electrode material, which resulted in further accumulation of

183 liquid. The catholyte generated was transparent in colour and odourless, whilst the catholyte

184 generated under open-circuit, was similar to the anolyte (Figure 5B). The level of pH and 185 conductivity was a function of the presence or absence of the external load. Figure 6 shows 186 that both $\mathrm{pH}$ and conductivity of the catholyte in the working MFCs (T1, T2 and T3) was

187 significantly higher than that of the catholyte of the open-circuit MFCs. Moreover, the 188 difference in $\mathrm{pH}$ between the anolyte and catholyte was more marked for the working MFCs 189 rather than the MFCs under open-circuit, which showed no significant changes indicating anion and $\mathrm{pH}$ splitting mechanism in working MFCs (T- working). 

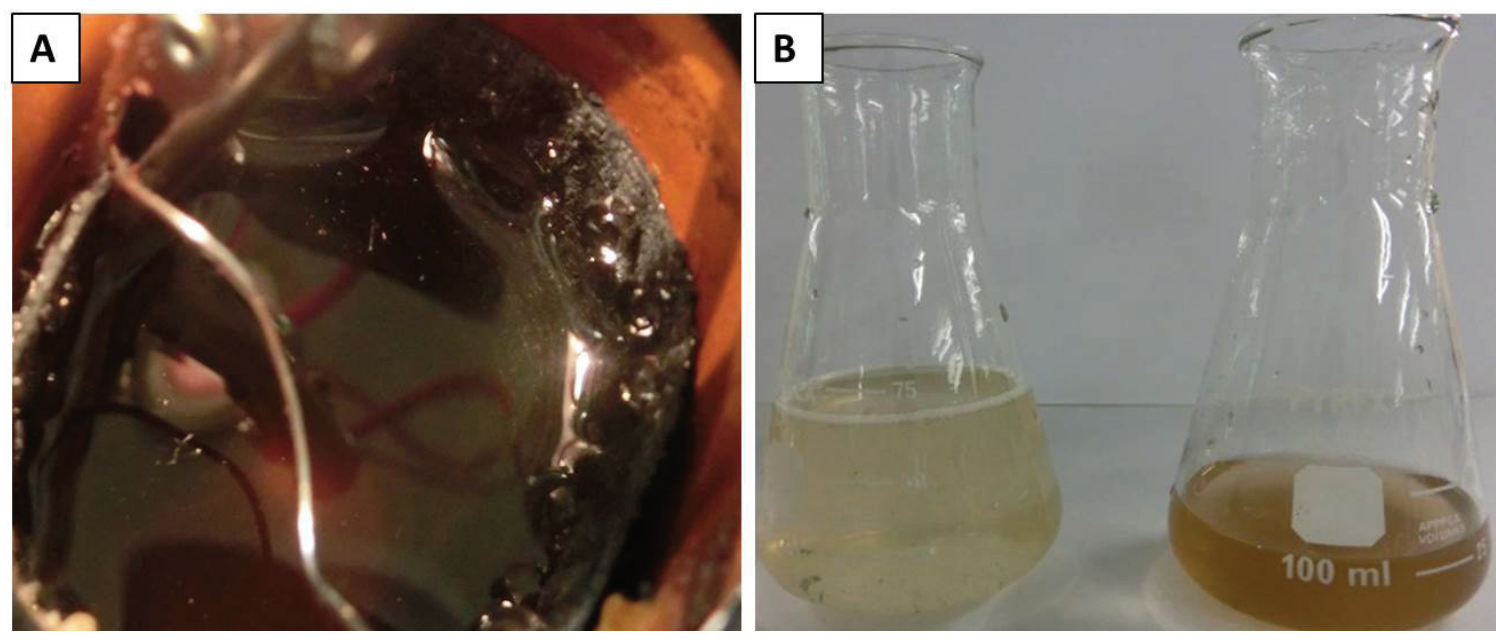

192 Fig 5. A) Catholyte formation, B) the amount of catholyte produced under closed circuit (left) 193 and open circuit conditions (right).

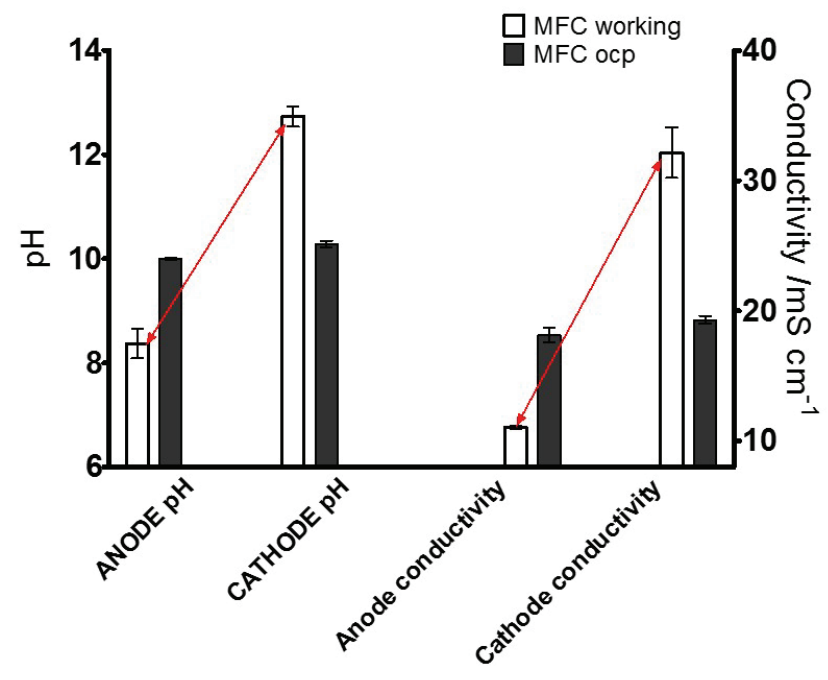

195 Figure 6. Conductivity and $\mathrm{pH}$ of MFC catholyte, with respect to the anolyte, in working and open circuit conditions. Arrows highlight the difference in these two conditions.

198 During the 7 days of continuous operation under load, for the working MFCs, it was clearly 199 shown that the COD was significantly reduced, as illustrated in Figure 7 below. 


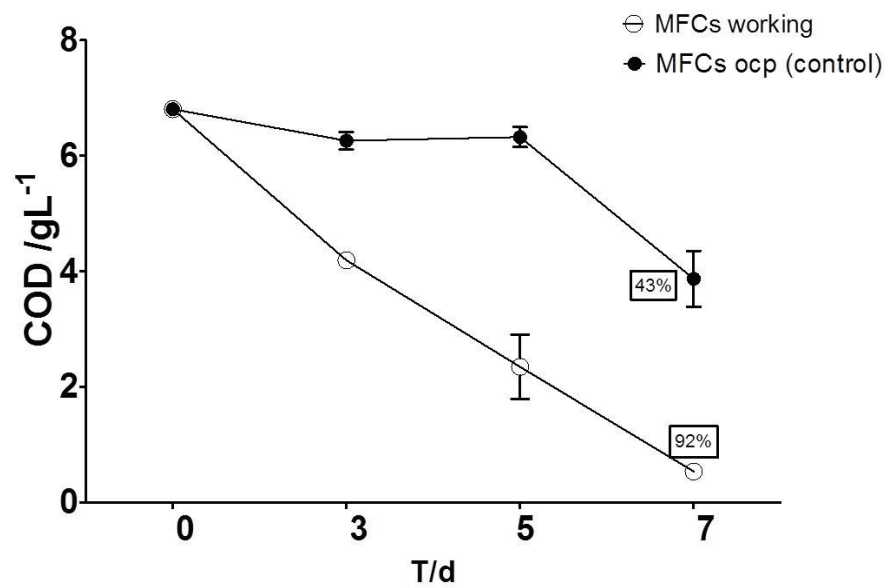

201 Figure 7. Temporal COD reduction from the working MFCs against MFCs in open circuit.

203 As can be seen in Figure 7, the level of COD reduction achieved by the ceramic MFCs was of 204 the order of $92 \%$, and this was also true for the underperforming T2 MFC. It may be assumed

205 that other antagonistic reactions were taking place in this unit in particular, and this should 206 form part of a separate investigation.

\section{3.3. Powering the LED}

208 To show the potential of the cylindrical MFCs to power real world applications, the working 209 MFCs were used to successfully operate a red LED directly, at a constant voltage of $\sim 1.7 \mathrm{~V}$.

210 The LED was shown to be operated continuously as long as the substrate (0.1M sodium

211 acetate) was fed to the MFCs. This substrate was fed at the beginning of the week and was 212 not replenished until the end of the test as shown in figure 8. During the anolyte exchange for 213 feeding, the LED would stop working for a short period of time, until the MFC performance 214 recovered to the previous levels, at which point the LED would turn ON once again.

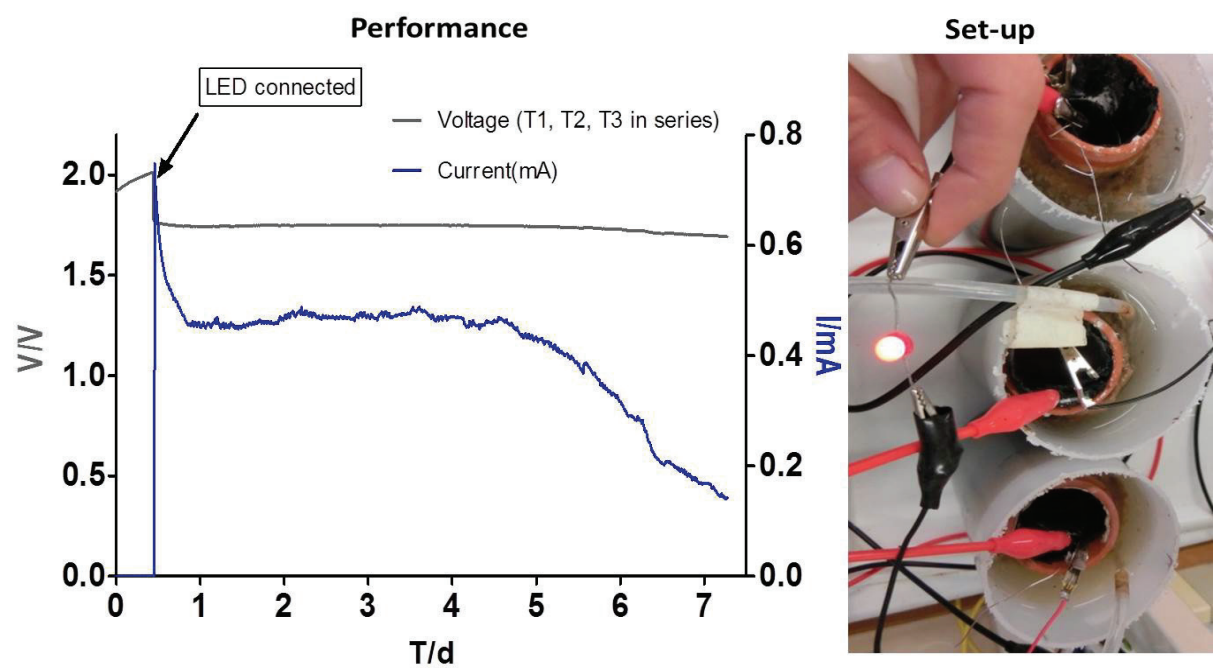


216

217

218

219

220

221

222

223

224

225

226

227

228

229

230

231

232

Figure 8. Voltage of the LED and current generated from the 3 working MFCs connected in series, and directly powering the single LED.

3.4. Carbon Capture via electrodialysis
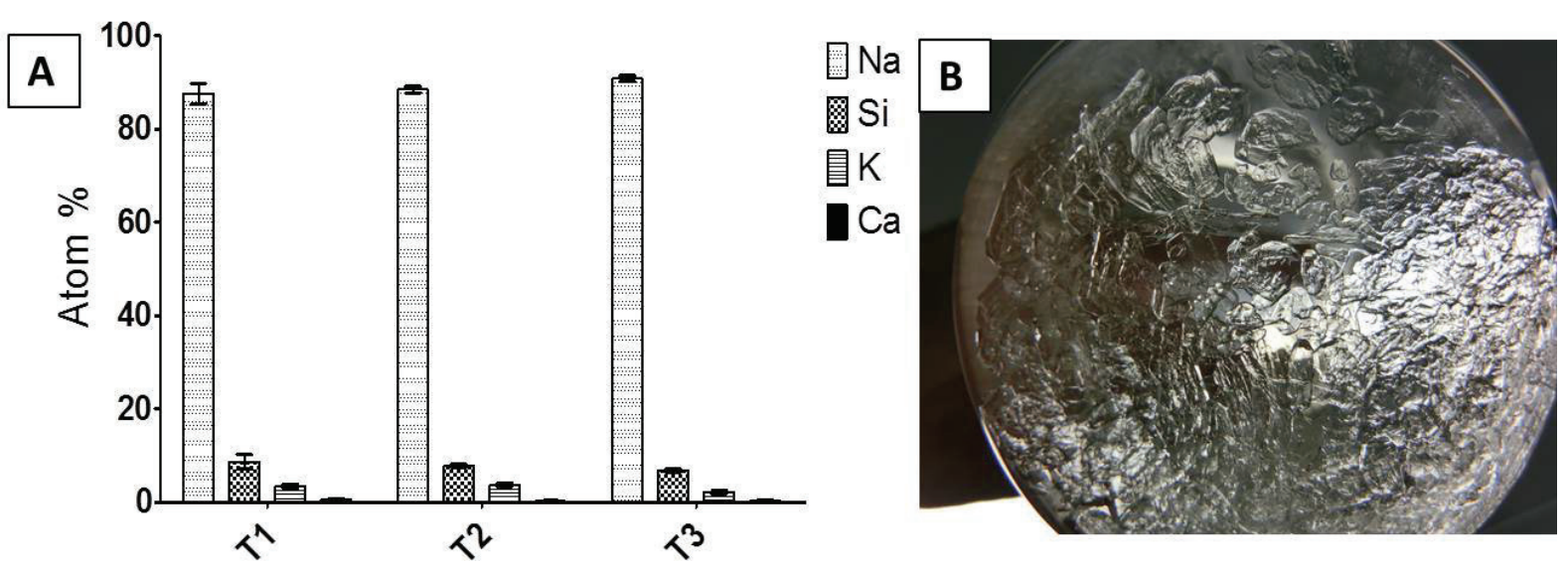

Figure 9.A) EDX profile representing \% of detected elements in crystallised salts from the evaporated liquid sample, B) crystalline structure of catholyte formed on the bottom of the glass container (right).

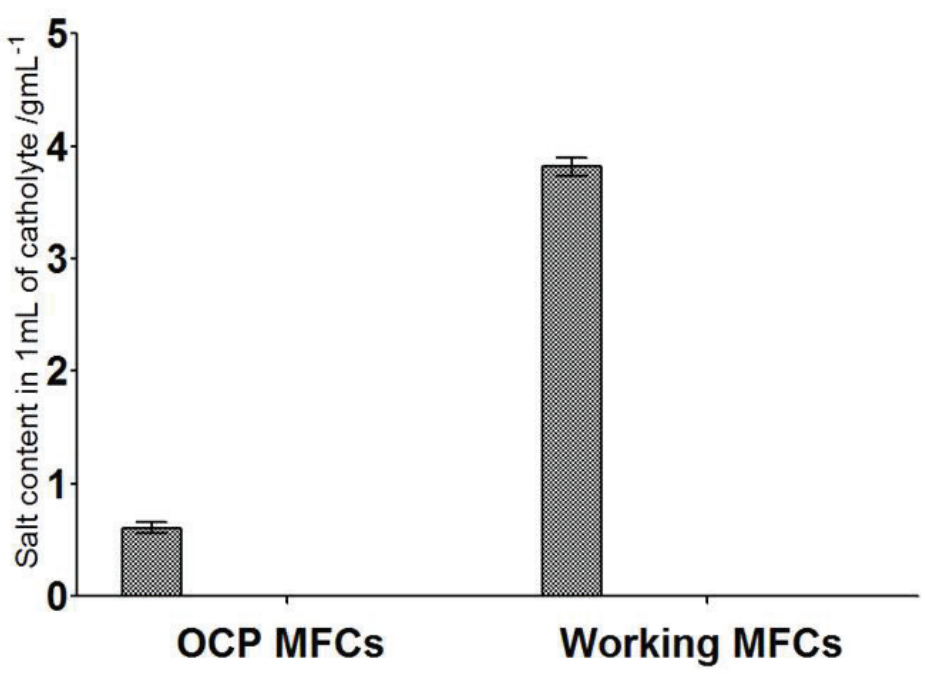

Figure 10. Comparison between the amounts of salts generated in the collected catholyte, for the open circuit and loaded MFCs.

Further analysis of the accumulated salts shows that apart from high $\mathrm{pH}$ and high concentration of the solution, the salts formed following the evaporation of samples, showed on average $88 \%$ content as sodium salt. As can be seen in Figure 10, a significantly higher amount of salts migrated from the anode to the cathode in the loaded MFCs is far higher than 
the solid mass measured from the open circuit units; this is also proportional to the amount of

234 liquid catholyte formed. If the amount of salts generated under open circuit (no charge transfer) is deducted from the amount of salts generated by the loaded MFCs, then a net weight of $3.3 \mathrm{~g} / \mathrm{mL}$ can be directly attributed to electro-osmotic drag and ORR. In addition, the chemical properties of the catholyte generated under load conditions, such as high $\mathrm{pH}$, high conductivity and high salinity, may be suitable as a disinfection agent, which is forming part of our continuing research. Initial findings suggest that the chemical composition of the catholyte is consistent with mineral phases such as trona, $\left(\mathrm{Na}_{3}\left(\mathrm{CO}_{3}\right)\left(\mathrm{HCO}_{3}\right) 2 \mathrm{H}_{2} \mathrm{O}\right)$ and $\mathrm{Na}_{2}$ $\mathrm{CO}_{3} 2 \mathrm{H}_{2} \mathrm{O}$. Trona is a mixture of two phases of sodium carbonate/bicarbonate (data not shown).

\section{Discussion}

The key issue for the implementation of Carbon Capture and Storage (CCS) is the high cost of sorbents. The current practice for CCS is effectively capturing $\mathrm{CO}_{2}$ in the flue gas by an alkaline hydroxide absorbing solution, in order to react and form an alkaline carbonate solution with a normal gas-liquid absorption tower; for example, $\mathrm{CO}_{2}+\mathrm{MOH} \rightarrow \mathrm{MHCO}_{3}$ where $\mathrm{M}$ represents a metal such as sodium. The use of alkaline sorbents have been shown as a method for carbon capture [27] and the MFC could be a method for a sorbent production that produces electrical energy [28]. Electro-dialysis is a process that depends on the principle that most dissolved salts are positively or negatively charged and they will migrate to electrodes with opposing charges. Electro-dialysis systems do this by using expensive membranes [29]. In the MFC presented here, wastewater was supplemented with sodium acetate and utilised as the carbon energy source for the microorganisms, which break it down for consumption. This dissociates the sodium ions, which migrate over to the cathode through the ceramic material, as a direct consequence of the electricity being generated, thus effecting electrodialysis and ion separation. This method is truly cost effective because inexpensive materials and simplified methods of preparation were employed. For example, carbon veil used as a gas diffusion matrix is 100 times cheaper than 30\% PTFE pre-treated, commercially available carbon cloth (e.g. as supplied by fuelcellearth). The calculated cost of in house prepared activated carbon cathodes is $120 £ / \mathrm{m}^{2}$ which is 7 times cheaper to using the same coating on carbon cloth. With an electric field in the system, the process of anolyte dissociation takes place with the use of membrane systems. Electrical potential applied to the ion exchange separators will involve the ion movement within the reactor. This has been the basis for electrodialysis 
267 studies where the potential is set externally to drive the dialytic process or desalination.

268 Recently, it was proposed that alkali production in a cathodic chamber of a microbial

269 electrolysis cell is possible, when a high electrical potential is applied and additional

270 catholyte is externally supplied at high salt concentrations [8]. This exploration has been

271 showing the potential of alkali production in situ in electrodialysis systems [30] resulting in

272 rather complicated designs [31]. This study is aiming to demonstrate the advantages of simple

273 designs to make the MFC technology even more attractive.

274 The novelty of the use of ceramic material to (i) perform the co-generation of electricity and

275 electro-dialytic functions and (ii) extract water and (iii) produce alkaline catholyte, is

276 bringing this closer to implementation in real domestic environments as well as wastewater

277 treatment plants. It is shown here that water desalination can be accomplished without

278 electrical energy input as a result of electricity generation. The fact that the power does not

279 decrease during this operation, whilst the cathode electrode has been flooded, might be

280 attributed to the high salt concentration and increased conductivity. Electrical resistance of

281 ion exchange membranes strongly increases with the decrease of solution concentration

282 especially in low strength solutions [32,33]. Moreover the electrical power produced from

283 mixing saline solutions is rooted in the membrane-based energy conversion mechanisms such

284 as reversed electrodialysis [34,35]. The salinity gradient energy is a very promising avenue

285 for electricity generation and in this design, it might be an additional driving element.

286 Ceramic based MFC cylinders have been previously shown in standard anode-cathode

287 configurations [20] to remove ammonium [36] and energise practical applications [37]. The

288 submerged MFC design described in the present study represents a true integration of two

289 BES systems (MFC and MEC) into one simple design that could be used in a real

290 environment. Scaled-up versions of the MFCs presented here have already been demonstrated

291 as (i) a stack of 40 MFC reactors set up to treat urine and charge a mobile phone in real-time

292 [38] and (ii) a stack of 288 MFC reactors operating directly from urinals to power indoor

293 lighting [39]. Open to air cathode coupled with ceramic membranes could be used both for

294 electricity generation and filtration of wastewater to regenerate water. Real life

295 implementation of microbial fuel cells presented herein that does not require strictly

296 controlled conditions or high maintenance, has the potential to play a major role in

297 developing sustainable urban wastewater systems. Considering the amount of wastewater

298 produced globally and the potential energy stored within it, it is important that MFC

299 technology development should perhaps be pursued with real word applications in mind. This 
work is aiming at efficient industrial-scale development that would recover energy from wastewater using a terracotta tubular design, enhancing functionality of the MFC.

\section{Conclusions}

This work has shown a novel, ceramic based MFC with an internal cathode that can perform the function of the co-generation of electricity and linked formation of catholyte from wastewater. MFC electrical performance is directly related to the amount of accumulated catholyte in the internal cathode chamber. The formation of catholyte is solely due to the MFC operation that drives the electro-dialytic transport of ions from the anode to the cathode and results in active electroosmotic extraction of water. The properties of formed catholyte include high $\mathrm{pH}$ and high salt concentration, which demonstrates the potential of in situ production of alkaline sorbent from wastewater. Pt-free MFC produced caustic sorbents that can fix carbon dioxide into carbonates and bicarbonates through wet scrubbing showing cost effective microbially assisted electrosynthesis.

This work reports simultaneous extraction of clean water from wastewater, elemental recovery and power production using a low maintenance, simple to make Microbial Fuel Cell system encouraging further scale-up into real world applications.

\section{Acknowledgement}

The work was funded by the Engineering and Physical Sciences Research Council EPSRC CAF EP-I004653/1 and EP/L002132/1. The scale-up part of the work for the Re-Invent the Toilet Fair in India has been supported by the Bill \& Melinda Gates Foundation, grant no. OPP1094890. The authors would like to thank Dr David Patton, from the University of the West of England and Dr Hazel Sparkes from the University of Bristol for the valuable expertise and analysis of the catholyte samples, and also Dr Jonathan Winfield for his general advice.

\section{References}

[1] E.S. Heidrich, T.P. Curtis, J. Dolfing, Determination of the internal chemical energy of wastewater., Environ. Sci. Technol. 45 (2011) 827-32. doi:10.1021/es103058w.

[2] D.R. Lovley, K.P. Nevin, A shift in the current: new applications and concepts for microbe-electrode electron exchange., Curr. Opin. Biotechnol. 22 (2011) 441-8. doi:10.1016/j.copbio.2011.01.009. 
[3] R. Rozendal, Effects of membrane cation transport on $\mathrm{pH}$ and microbial fuel cell performance, Environ. Sci. Technol. 40 (2006) 5206-5211. http://pubs.acs.org/doi/abs/10.1021/es060387r (accessed May 08, 2014).

[4] K. Rabaey, J. Keller, Microbial fuel cell cathodes: from bottleneck to prime opportunity?, Water Sci. Technol. 57 (2008) 655-9. doi:10.2166/wst.2008.103.

[5] D. Call, B.E. Logan, Hydrogen production in a single chamber microbial electrolysis cell lacking a membrane., Environ. Sci. Technol. 42 (2008) 3401-6. http://www.ncbi.nlm.nih.gov/pubmed/18522125.

[6] R.A. Rozendal, E. Leone, J. Keller, K. Rabaey, Efficient hydrogen peroxide generation from organic matter in a bioelectrochemical system, Electrochem. Commun. 11 (2009) 1752-1755. doi:10.1016/j.elecom.2009.07.008.

[7] P. Clauwaert, W. Verstraete, Methanogenesis in membraneless microbial electrolysis cells., Appl. Microbiol. Biotechnol. 82 (2009) 829-36. doi:10.1007/s00253-008-17964.

[8] K. Rabaey, S. Bützer, S. Brown, J. Keller, R. a Rozendal, High current generation coupled to caustic production using a lamellar bioelectrochemical system., Environ. Sci. Technol. 44 (2010) 4315-21. doi:10.1021/es9037963.

[9] K. Kinoshita, Carbon Electrochemical and Physicochemical Properties, John Wiley \& Sons, Ltd,., 1988.

[10] J.R. Kim, G.C. Premier, F.R. Hawkes, R.M. Dinsdale, A.J. Guwy, Development of a tubular microbial fuel cell (MFC) employing a membrane electrode assembly cathode, J. Power Sources. 187 (2009) 393-399. doi:10.1016/j.jpowsour.2008.11.020.

[11] K. Rabaey, R. a Rozendal, Microbial electrosynthesis - revisiting the electrical route for microbial production., Nat. Rev. Microbiol. 8 (2010) 706-16. doi:10.1038/nrmicro2422.

[12] I. Gajda, J. Greenman, C. Melhuish, C. Santoro, B. Li, P. Cristiani, et al., Water formation at the cathode and sodium recovery using Microbial Fuel Cells (MFCs), Sustain. Energy Technol. Assessments. 7 (2014) 187-194. doi:10.1016/j.seta.2014.05.001.

[13] Z. Ge, Q. Ping, L. Xiao, Z. He, Reducing effluent discharge and recovering bioenergy in an osmotic microbial fuel cell treating domestic wastewater, Desalination. 312 (2013) 52-59. doi:10.1016/j.desal.2012.08.036.

[14] F. Zhang, K.S. Brastad, Z. He, Integrating forward osmosis into microbial fuel cells for wastewater treatment, water extraction and bioelectricity generation., Environ. Sci. Technol. 45 (2011) 6690-6. doi:10.1021/es201505t.

[15] N.T. Hancock, T.Y. Cath, Solute coupled diffusion in osmotically driven membrane processes., Environ. Sci. Technol. 43 (2009) 6769-75. http://www.ncbi.nlm.nih.gov/pubmed/19764248. 
[16] D.H. Park, J.G. Zeikus, Improved fuel cell and electrode designs for producing electricity from microbial degradation., Biotechnol. Bioeng. 81 (2003) 348-55. doi:10.1002/bit.10501.

[17] M. Behera, P.S. Jana, M.M. Ghangrekar, Performance evaluation of low cost microbial fuel cell fabricated using earthen pot with biotic and abiotic cathode., Bioresour. Technol. 101 (2010) 1183-9. doi:10.1016/j.biortech.2009.07.089.

[18] F.F. Ajayi, P.R. Weigele, A terracotta bio-battery., Bioresour. Technol. 116 (2012) 8691. doi:10.1016/j.biortech.2012.04.019.

[19] M. Behera, P.S. Jana, T.T. More, M.M. Ghangrekar, Rice mill wastewater treatment in microbial fuel cells fabricated using proton exchange membrane and earthen pot at different pH., Bioelectrochemistry. 79 (2010) 228-33. doi:10.1016/j.bioelechem.2010.06.002.

[20] J. Winfield, J. Greenman, D. Huson, I. Ieropoulos, Comparing terracotta and earthenware for multiple functionalities in microbial fuel cells., Bioprocess Biosyst. Eng. 36 (2013) 1913-21. doi:10.1007/s00449-013-0967-6.

[21] X. Zhang, X. Xia, I. Ivanov, X. Huang, B.E. Logan, Enhanced activated carbon cathode performance for microbial fuel cell by blending carbon black., Environ. Sci. Technol. 48 (2014) 2075-81. doi:10.1021/es405029y.

[22] M. Ghasemi, S. Shahgaldi, M. Ismail, B.H. Kim, Z. Yaakob, W.R. Wan Daud, Activated carbon nanofibers as an alternative cathode catalyst to platinum in a twochamber microbial fuel cell, Int. J. Hydrogen Energy. 36 (2011) 13746-13752. doi:10.1016/j.ijhydene.2011.07.118.

[23] C. Santoro, K. Artyushkova, S. Babanova, P. Atanassov, I. Ieropoulos, M. Grattieri, et al., Parameters characterization and optimization of activated carbon (AC) cathodes for microbial fuel cell application., Bioresour. Technol. 163C (2014) 54-63. doi:10.1016/j.biortech.2014.03.091.

[24] X. Li, X. Wang, Y. Zhang, N. Ding, Q. Zhou, Opening size optimization of metal matrix in rolling-pressed activated carbon air-cathode for microbial fuel cells, Appl. Energy. 123 (2014) 13-18. doi:10.1016/j.apenergy.2014.02.048.

[25] N. Degrenne, F. Buret, B. Allard, P. Bevilacqua, Electrical energy generation from a large number of microbial fuel cells operating at maximum power point electrical load, J. Power Sources. 205 (2012) 188-193. doi:10.1016/j.jpowsour.2012.01.082.

[26] I. Ieropoulos, J. Greenman, C. Melhuish, Microbial fuel cells based on carbon veil electrodes: Stack configuration and scalability, Int. J. Energy Res. 32 (2008) 12281240. doi:10.1002/er.1419.

[27] K.S. Lackner, The thermodynamics of direct air capture of carbon dioxide, Energy. 50 (2013) 38-46. doi:10.1016/j.energy.2012.09.012. 
[28] Gajda, I., J. Greenman, C. Melhuish, I. Ieropoulos, Artificial photosynthesis coupled with electricity generation - microbial fuel cells as artificial plants, in: ALIFE 14 Fourteenth Int. Conf. Synth. Simul. Living Syst. ALIFE Work. Exploit. Synerg. between Biol. Artif. Life Technol. Tools, Possibilities, Examples, 30 July-2 August 2014, NY, USA., 2014.

[29] C. Huang, T. Xu, Electrodialysis with Bipolar Membranes for Sustainable Development, Environ. Sci. Technol. 40 (2006) 5233-5243. doi:10.1021/es060039p.

[30] M. Chen, F. Zhang, Y. Zhang, R.J. Zeng, Alkali production from bipolar membrane electrodialysis powered by microbial fuel cell and application for biogas upgrading, Appl. Energy. 103 (2013) 428-434. doi:10.1016/j.apenergy.2012.10.005.

[31] X. Zhu, M.C. Hatzell, R.D. Cusick, B.E. Logan, Microbial reverse-electrodialysis chemical-production cell for acid and alkali production, Electrochem. Commun. 31 (2013) 52-55. doi:10.1016/j.elecom.2013.03.010.

[32] P. Długołęcki, B. Anet, S.J. Metz, K. Nijmeijer, M. Wessling, Transport limitations in ion exchange membranes at low salt concentrations, J. Memb. Sci. 346 (2010) 163171. doi:10.1016/j.memsci.2009.09.033.

[33] F. Harnisch, U. Schröder, F. Scholz, The suitability of monopolar and bipolar ion exchange membranes as separators for biological fuel cells., Environ. Sci. Technol. 42 (2008) 1740-6. http://www.ncbi.nlm.nih.gov/pubmed/18441829.

[34] J.W. Post, J. Veerman, H.V.M. Hamelers, G.J.W. Euverink, S.J. Metz, K. Nymeijer, et al., Salinity-gradient power: Evaluation of pressure-retarded osmosis and reverse electrodialysis, J. Memb. Sci. 288 (2007) 218-230. doi:10.1016/j.memsci.2006.11.018.

[35] R.E. Pattle, Production of Electric Power by mixing Fresh and Salt Water in the Hydroelectric Pile, Nature. 174 (1954) 660-660. doi:10.1038/174660a0.

[36] D.A. Jadhav, M.M. Ghangrekar, Effective ammonium removal by anaerobic oxidation in microbial fuel cells., Environ. Technol. (2014) 1-23. doi:10.1080/09593330.2014.960481.

[37] I. Ieropoulos, P. Ledezma, A. Stinchcombe, G. Papaharalabos, C. Melhuish, J. Greenman, Waste to real energy: the first MFC powered mobile phone., Phys. Chem. Chem. Phys. 15 (2013) 15312-15316. doi:10.1039/c3cp52889h.

[38] Gatesfoundation.org, Urine-tricity, Reinvent-the-Toilet-Fair-India-2014-Program. (2014) Page 13. http://www.gatesfoundation.org/ /media/GFO/Documents/What-WeDo/Reinvent-the-Toilet-Fair-India-2014-Program.pdf.

[39] University of the West of England, "Pee-power" to light camps in disaster zones, (2015). http://info.uwe.ac.uk/news/UWENews/news.aspx?id=3050. 